This is a pre-publication version. The published version can be found at: Ellis-Hill C, Payne S Ward C (2008) Using stroke to explore the Life Thread Model: An alternative approach to understanding rehabilitation following an acquired disability Disability and Rehabilitation, 30(2): 150 - 159 ISSN 09638288 print/ISSN 1464-5165 online DOI: 10.1080/09638280701195462

\title{
Using stroke to explore the Life Thread Model: An alternative approach to understanding rehabilitation following an acquired disability
}

Caroline Ellis-Hill School of Health Professions and Rehabilitation Sciences, University of Southampton, Southampton,

Sheila Payne International Observatory on End of Life Care, Institute for Health Research Lancaster University, Lancaster

Christopher Ward University of Nottingham Division of Rehabilitation and Ageing, School of Community Health Sciences, Derby City General Hospital, Derby, UK 


\begin{abstract}
The purpose of this paper is to introduce the Life Thread Model, which incorporates established psychological and social theory related to identity change following an acquired disability. It is supported by a growing body of empirical evidence and can be used to broaden our understanding of service provision in rehabilitation. We suggest that a limited appreciation of social and psychological processes underpinning rehabilitation has led to different agendas for patients and professionals, lack of recognition of power relationships, negative views of disability, and insufficient professional knowledge about the management of emotional responses. The Life Thread Model, based on narrative theory and focusing on interpersonal relationships, has been developed following ten years of empirical research. Using the model, the balance of power between professionals and patients can be recognized. We suggest that positive emotional responses can be supported through (a) endorsing a positive view of self, (b) 'being' with somebody as well as 'doing' things for them; and (c) seeing acquired disability as a time of transition rather than simply of loss. This model highlights the usually hidden social processes which underpin clinical practice in acquired disability. Recognition of the importance of discursive as well as physical strategies widens the possibilities for intervention and treatment.
\end{abstract}

Keywords: Stroke, narrative, identity, rehabilitation, model 


\section{Introduction}

A stroke is 'an intensely personal experience involving the rebuilding and restructuring of an individual's world' [1, p. 307]. The aim of this article is to introduce a new framework, the Life Thread Model, which illuminates the psychological and social processes associated with transition following an acquired disability. We use stroke as an example of a sudden and dramatic life change. We first discuss the limitations of what could be referred to as 'traditional' rehabilitation approaches. We then consider the contribution of sociological and psychological narrative research, exploring the effect of acquiring a chronic disability on life and identity [2], and introduce the model itself. We present initial empirical data to support the model. Finally we will discuss the implications for rehabilitation service provision, including recognition of the importance of interpersonal relationships, which can lead to the rebuilding of more positive identities and emotional responses. Limitations of the 'traditional' rehabilitation model

Over the last 30 years rehabilitation service provision has been dominated by the healthcare professionals who provide it. Researchers have responded by using objective measures to study and monitor services. The predominance of professional values in training, practice and research leads to a circular system which discourages the contribution of patients and their families.

New opportunities to understand the perspectives of patients and families have arisen from developments in the social sciences. The lived world is no longer viewed solely or even largely in terms of material aspects (the objective world which can be touched, and measured). There has been growing recognition of the importance of social reality, comprising rules, meanings and understandings which shape our understanding of our situation. Social reality is constructed through sharing of talk - or discourse - in the social arena $[3,4]$. From a sociological perspective two sorts of social reality can be discerned within healthcare - that of the professional and that of the person receiving the service [5]. Research has shown that there is still a large gap between professional and personal understandings and expectations [5 - 7]. For example, healthcare professionals often view physical recovery following a stroke as the focus of intervention, whereas Doolittle [5] found that although people themselves saw physical improvement as important, the focus for them was returning to their pre-stroke life. The gap between professional and personal 
realities reduces the effectiveness of rehabilitation in several ways, as discussed below.

\section{Lack of understanding of motivations}

The failure to take account of a person's social reality can lead to a lack of understanding of people's motivations. The behaviour and actions of the person are based within their understandings of their social reality, their daily life experience, not on the logical assumptions which professionals may expect. The experience of chronic illness goes 'far beyond living with the mere loss of functional ability' [8, p. 181] rather it entails 'dwelling in the world in a totally different way' $[8, \mathrm{p} .181]$. Treatment advice or information from a healthcare professional will be seen as irrelevant if it does not fit into the individual's shifting social reality. Conversely, health professionals may be less able to provide appropriate treatment and support if key issues in the person's social reality (such as personal preference, finances and opportunity) are not recognized.

\section{Expert status}

Professionals providing services automatically figure as experts in the world as they see it. This unintentionally puts people receiving support at a disadvantage; they can become passive recipients of information, advice and treatment. Communication can then become one-way - from the healthcare professional to the person. As Mackay [9] suggested, 'doctors speak, the person with aphasia listens' (p. 812). Campbell and McCauley [10] suggest that while medical students are taught to 'take the history and examine the patient' it would also be helpful to 'take the patient and examine the history'. In a study of people living with diabetes, Paterson [11] found that professionals, despite speaking the language of partnership, often maintained power through the use of subtle and largely unrecognized discursive strategies. These included preventing people living with diabetes from sharing their experiences, discounting the experiences of people with diabetes if their outcomes did not tally with medical expectations, using medical language which was not understood by lay people, and suggesting actions which were impracticable for social or financial reasons. The respondents described a 'partnership' in which people with diabetes were required to comply with professional views. This way of working is often unrecognized by healthcare professionals, who appear to be unaware of the tensions of power within their relationships. 


\section{Disability is seen as a loss}

Disability is seen in terms of deficit and loss within the 'traditional' discourse where the focus is the physical body and disability is defined by tasks an individual can no longer perform. Disability is linked with limitations, problems and difficulties not usually experienced by an able-bodied person. This supports the negative view that disabled people are in some way 'less than' other people. The idea of bereavement or loss following a stroke is more characteristic of the discourse of healthcare professionals than of disabled people themselves [12]. Within the 'traditional' rehabilitation discourse, people following stroke are seen as specific sorts of people with specific problems, linked very closely with their medical condition. Such discourse separates rehabilitation professionals from patients, who are seen as 'other' [13] and having limited future prospects.

\section{Limited professional knowledge about the emotional/ existential aspects of life}

There are many 'invisible' emotional difficulties facing people with an acquired permanent physical disability [14]. Currently mood disorder following stroke is poorly understood. Mood change has been ascribed both to the brain damage itself [15] and to a natural response to the level of disability experienced [16]. Within physical healthcare, psychological aspects of a person's care are typically referred to specialist staff such as clinical psychologists because psychological and emotional support is thought to be outside the expertise of most healthcare professionals [17]. Since clinical psychologists are in short supply, this attitude limits the potential of rehabilitation services to resolve emotional issues. Many disabled people have no help in managing their emotional problems.It can be seen that rehabilitation services are likely to be more effective if the social realities of service users are taken into account. The next section will discuss how social realities can be accessed in order to influence everyday practice.

\section{Narrative theory}

Over the last 30 years, researchers within the social sciences have placed increasing emphasis on the meaning and experience of chronic disabling illness conditions and on the negotiation of self and identity in everyday life [2]. Medical sociologists have developed concepts such as the biographically disruptive nature of chronic illness, the importance of narrative reconstruction, and the negotiation of selfhood and identity within healthcare [18 - 21]. Psychological research has explored the social processes which impact on the individual and 
sense of self [22]. McAdams [23] concludes that present identity is the result of creating a life story and that creation of narrative order is essential in giving one's life a sense of meaning and direction.

It can therefore be seen that our social reality is made up of how we see our life story (or life narrative ) in its past, present and future. Definitions of narrative tend to vary from a vague term such as storytelling [24] and life story [25] to specific definitions applying to rules of grammar [26]. Here we define a narrative as 'the re-creation of events and actions in a symbolic structured way so that the motives of the actors and the morality of the situation can be understood by self and others' [27, p. 132].

In order to appreciate the importance of narratives it is necessary to explore their structure. A narrative is a re-creation of events, not a mere list of episodes. The teller attends to certain aspects of the events, ignores others, creates actors, sets them on a stage, and creates a storyline or plot describing the motives of the actors, so as to engage the listener. The storyline or plot is the basis of a narrative. Events are linked not because of categorical similarity but because they contribute to a plot $[28,29]$. Stories are told to convey messages to the listener. Narrative structure communicates moral values between the speakers. Events themselves are free of values; whether an event is good or bad depends on the framework which is used for understanding. In order to appreciate a plot the audience must have shared cultural norms, a common understanding. So although every life story is individual and unique there are historical and cultural commonalties. Narratives not only re-enact experience in the telling, but reinforce social and cultural structures of society through their telling. These moral and social underpinnings of narrative have been recognized as playing a key part in the interpretation and experience of illness [30].

There has been increasing recognition of the importance of narrative approaches in medicine in general [31 - 33] and specifically in rehabilitation [34-37]. However it appears that narrative principles are difficult to apply in practice because the concepts of narrative and social reality are so abstract. The model we present here is based on the narrative approach and has been incorporated into undergraduate and postgraduate teaching by the first author. Students have reported that the model is extremely useful when considering their 
own practice.

\section{The Life Thread Model}

The first author (CEH) has developed a discursive model derived from the psychological and sociological work described above and tested with empirical data [38 - 41]. The metaphor for the model is life threads which represent the stories or strands of ourselves that we create and re-create though life.

Figure 1 represents the basis of the Life Thread Model. The threads represent the variety of stories that we can tell about ourselves.

\section{Figure 1 here -see Figures at end of document}

They represent past memories and future plans. Some life threads and stories remain throughout our lives (our role as somebody's son or somebody's daughter remain) but others come and go: Identities such as having very long hair or being the fastest runner at school may be important in childhood but may not be useful stories to share in adulthood. The life threads or stories help to create a past and future life, creating a sense of the individual's identity, situation and future possibilities.

Figure 2 represents the social aspect of stories. Stories or narratives are created between people (a teller and an audience).

\section{Figure 2 here}

The two close threads in the centre of the figure might represent a couple who have many shared memories and shared future plans. The thread looping down to meet the central thread might represent a person going into hospital: For a short period of time they are living and working very closely with healthcare professionals, with shared plans and shared goals and then they leave, never to meet again. Stories people tell about themselves are influenced by wider society, forming parallel threads. Such meta-narratives form the discursive repertoire and cultural values in society. For example, women in business are often portrayed as being aggressive whereas men acting in the same way are portrayed as assertive. Disabled people are portrayed as being brave and heroic, rather than just being ordinary people making their way in the world. 
According to the life-threads approach, identity and sense of self are not fixed within a person, but are created and constantly re-created between people as life proceeds. Discursive networks support people throughout life and contribute to a sense of shared understanding and belonging.

A key aspect of the Life Thread Model is that a sense of coherence and stability is created through stories [42]. Continuity is essential for psychological well-being and personal integration and for an individual to experience him or herself as one person, despite change and disruption, throughout the life cycle [43]. Through life narratives, individuals create links between their past which is known and their future which is unknown. This process provides confidence in the future, with the assumption that the world will carry on as it has in the past. Research has shown that the sense of coherence and predictability is challenged when a person faces a diagnosis of a long-term medical condition. People enter a world which is experienced as unfamiliar [1]; usual rules which guide behaviour and action are lost. Figure 3 represents the life threads of a person who has experienced a stroke.

\section{Figure 3 here}

The predictability of usual life is suddenly lost - the life threads are broken and frayed. As mentioned previously, medical sociologists have drawn attention to this biographical disruption [18]. The first author has shown empirically that this occurs in stroke. In a study of 26 people, it was found that people reported that their self-concept had changed in relation to their pre-stroke self (past-present self-concept score; $p$ < 0.0003) [39]. This was also found in a study of 38 people following stroke (past-present self-concept scores, $p<0.0000$ ) [38].

The qualitative nature of this disruption was well described by one of the participants:

It's a very severe thing to happen to anyone

it's not like getting a-y'know - having a broken

arm or something like that

which incapacitates you for a couple of

months put your arm in plaster

and normally just take the plaster off

and you get back to where you were before [1364/1]

.... you lead a normal life one day 
And within a matter of minutes, overnight it all comes to an end.

[38, p. 727]

Such findings indicate that people are facing not only physical challenges or pain, but also major psychological and existential challenges to their sense of self. Who are they now? Who are they going to be in the future? Murray and Harrison [14], working with people following a stroke, reported that the 'loss of me' meant that the participants often felt distanced from their new selves so that their own personhood has a strangeness and unfamiliarity. In order to move on with their life and make sense of their new worlds and the new 'me', the person needs to be able to manage the life threads which make up the wider rope (as shown in

\section{Figure 4)}

\section{Figure 4 about here}

The processes involved in 'trying to find the new me' and learning the rules in the new world are often not recognized within healthcare and they are still poorly understood [44]. Kralik et al. [45] have explored this area with people with rheumatoid arthritis and have conceptualized part of the process as a quest for ordinariness - a return to a state of affairs where the world can be taken for granted. They identified processes such as pacing, planning and prioritizing, balancing, testing out, experimenting, all of which need energy and enthusiasm in order to achieve some sense of predictability. Ellis-Hill [38], exploring the life narratives of ten couples following a stroke, found that even 12 months later most respondents had still not achieved this. A year after his stroke, one participant stated that:

'Cause the big, the big day I

want is to be able to get up

and not even think about doing it, you know

what I mean

I think that might happen one day, you

know I'll just get up like you do

without thinking about

walking I've still got to

get up there and stand up

and get my leg just one

leg out ready to take 
and move forward you know push my leg

through all this sort of thing, all these

motions

I've still got to think about it. [1037/3] [38, p. 99]

The Life Thread model suggests that rehabilitation processes are not merely physical and that discursive psychological and social processes are also involved. Carpenter [46] described how long-term survivors of spinal cord injury who, defined themselves as having successfully adapted, had not improved physically over time, but had re-defined disability. Rather than seeing themselves as 'victims' they came to see themselves as 'experts' and recreated their own definitions of disability, moving away from inadequacy or limitation.

\section{Definition of rehabilitation}

When the Life Thread Model is used, it can be seen that the focus for rehabilitation is the person actively trying to make sense of what has happened in their lives and trying to learn the new rules. This leads to the following definition of rehabilitation: Through rehabilitation, involving engagement in physical, psychological and social processes, people can learn how to live a life that is not dominated by their disability.

Described in these terms, rehabilitation belongs to the person, it is their process. Within research and clinical practice, rehabilitation is a term which seems to belong to the healthcare professional - professionals 'provide' rehabilitation, people are 'rehabilitated.' Exploration of discursive practices has shown that words construct as well as reflect accepted frameworks in the world [4]. In the following section the implications of using an alternative framework the Life Thread Model - on clinical practice will be discussed in more detail.

\section{Implications for clinical practice}

The centrality of the patient within healthcare services has been an important theme in recent UK policy documents such as the NHS Plan [47] and the National Service Frameworks $[48,49]$. Healthcare professionals can use the Life Thread Model to ensure that patients' social realities are central to their everyday practice.

\section{Power within rehabilitation services}

The Life Thread Model highlights the importance of relationships within healthcare and the 
balance of power which needs to be constantly recognized and addressed for successful rehabilitation to take place. As mentioned previously, narratives are created between people. The degree to which personal and professional realities contribute to shared healthcare narratives will define the balance of power within healthcare relationships. The Life Thread Model encourages practitioners to consider how often their interactions with patients are governed by professional agendas rather than enabling patients to share their own concerns. Therapeutic relationships cannot be effective without listening to people, and helping them to create more positive social realities. An issue which is often raised by healthcare professionals is that they do not have the time to listen to people. However, research suggests that it is possible to appreciate another's social reality within the time that usual interactions take place. In a study of 35 general practice case studies, Barry et al. [50] found four communication patterns: (i) 'strictly medicine', which was adequate for simple acute physical problems, (ii) 'ignored' and (iii) 'blocked', where people were blocked or ignored when they attempted to introduce issues, and (iv) 'mutual' where both doctor and patient engaged with the overall account. They found that it was the style of the consultation rather than the length of time that was different between these groups. Appreciating and co-constructing social realities is a challenging task for professionals. Polaschek [51] investigated the extent to which nurses can incorporate the client's social reality during negotiated care in renal therapy and identified the tension between being purely a technician at one extreme or a mere sympathizer at the other.

Techniques for enhancing narrative listening include (a) using exploring phrases such as "Tell me about.................", (b) using circular questions which aim to open up rather than close

down narratives for example "That must have been hard for you, can you tell me how you feel about it?', and (c) reflection - reflecting back and responding to the exact words of the patient. See Launer [52] for more details of these techniques.

\section{Emotional/existential aspects of life}

The Life Thread Model expressly highlights the usually 'invisible' [14] emotional difficulties facing people with an acquired permanent physical disability. Following an initial stroke people lose their usual rules, and the coherence in their lives; they are literally 'lost' and can feel an acute sense of isolation as their experiences cannot be shared and appreciated 
by others [38]. This was described well by one of the wives after a year of living with stroke.

Erm...... it's a 24 hour-a-day job really you know

I don't think people realize they

don't, they look at somebody

unless they're sat there all twisted up

and his face all distorted like it was in the

beginning then they could see that there was

something

Looking at Bob now when he's sat in his

wheelchair you think what the hell's he doing

in the wheelchair [121/3]

[38, p. 123]

People have entered a new world and social reality and often it is difficult for other people living their usual lives to appreciate the changes and challenges facing people living with a stroke.

The Life Thread Model contributes to understanding anxiety and depression following a stroke. In two studies, levels of anxiety and depression following a stroke were not necessarily linked to physical or self-care skills but were highly correlated with the degree to which people felt 'lost' [38,39]. It is difficult to determine cause and effect (i.e., anxious people may feel more 'lost') but it may be expected that if it is possible to help the person create a coherent connection between past and future life, it would be expected that their mood levels would improve. Using the Life Thread Model it can be seen that sharing life narratives is central to everyday practice. This gives all healthcare professionals a way of providing basic supportive psychological and emotional care. The details of this care are discussed further in the next section.

\section{Supporting a positive sense of self Respecting personhood}

Using the Life Thread Model, one of the key activities facing a person following a diagnosis of an acquired long-term physical disability is to develop a new positive sense of self. When facing life-changing events, a great deal of active work is needed to create a positive current and future self. Following diagnosis, when a person's sense of self is particularly fluid (see 
Figure 3), healthcare staff will have a powerful effect in either a positive or negative way. People may feel vulnerable and isolated, with no-one understanding their situation. This sense of isolation may decrease as a result of being allowed to share experiences and ideas. Healthcare staff may report that they do not know how to speak with people about emotional issues; however in a study exploring communication with people with breast cancer, Burkitt Wright et al. [53] found that often the respondents did not want to talk about emotional issues directly. They needed healthcare professionals who would ask for and respect their opinion. This sort of relationship in turn influenced their emotional state as they felt more supported and less isolated.

\section{'Being' as well as 'doing'}

The sharing of narratives is increasingly being recognized within healthcare as an intervention in itself [54]. Within healthcare, practitioners feel most comfortable when they are able to address and solve a problem and most uncomfortable when problems encountered cannot be solved. In order to protect themselves healthcare practitioners may structure interactions so that they do not hear about things that they feel powerless to resolve [55]. This will have the undesired effect of making the person feel more isolated. There can be many problems within healthcare which cannot be solved; but from a narrative perspective, it is important to share the experience and have it heard and validated. In a recent study by CEH a wife living with a stroke spoke of a significant experience for her while her husband was in hospital. She had been trying to get support from hospital staff but found this difficult until she met the sister on the ward. She said:

The sister was very nice on that

ward she was quite helpful

um I think I asked her about something

one day and she said "'Oh come out here

my dear

and sit down and we'll talk about it',

and I thought 'Well, you're the only person', you

know I don't think she did what I wanted her to do

but at least she talked about it you

know which none of the others have

done. [7/509]

When using the Life Thread Model within rehabilitation, 'being' with somebody is just as 
important as 'doing' something for them.

It is recognized that healthcare professionals using the Life Thread Model would expose themselves to their own as well as other people's emotional responses. Campbell and McCauley [10] highlight the need to be able to work within ambivalence and uncertainty, and the importance for practitioners of attending to their own responses to patients. We suggest that the systems and supervision which are in place to support professionals working within mental health services should be developed and incorporated into the culture for healthcare practitioners in other spheres such as physical rehabilitation.

\section{Disability - deficit and loss versus transition}

Negative views of disability can be challenged if disability is seen in the context of life narratives. When narratives are shared, the story invites the audience to enter into the lived world of the 'other', and to identify with the narrator. The audience is challenged to consider “'How would I have felt?', or “'What would I have done?', Life narratives bring together the worlds of narrator and listener as shared human experiences. The disabled person is seen as an ordinary person within an extra-ordinary situation, rather than being seen as 'other'. This creates the opportunity for further understanding and a more creative response focused within the narrator's life context.

Practitioners need to reflect on the context of the interactions that take place. When negotiating goals, are timescales short term, or do they take account both of life before disability and the more distant future? Are the goals only those which can be addressed by that particular practitioner or do they encompass wider aspects which might be addressed by others? Using a Life Thread approach, the focus is identity and personhood which can be maintained whatever the physical disability, through discursive practices. People who defined themselves as having adjusted to their spinal cord injury spoke about how they redefined 'disability' and 'normal' forthemselves [46]. One respondent spoke about how his wheelchair had developed from having a negative to a positive value for him and said:

Not being able to walk isn't so bad:

you get used to that aspect 
of it. Physically I'm pretty

good now.

I'm simply sitting down on the job more these

days. [46, p 621]

The Life Thread Model opens up many more possible therapeutic options than merely focusing on improving the physical body and physical environment alone.

By viewing the rehabilitation process as a transition rather than solely coming to terms with loss, researchers have suggested that rehabilitation entails re-structuring world views and developing new ways of living - which can be a very positive and creative process [56].

The Life Thread Model shares many attributes of the client-centred model of care $[7,57,58]$ in that it recognizes the importance of power within the healthcare practitioner-patient relationship, and the need for services which are responsive to people's needs and to their individual circumstances. However the Life Thread Model is more specific in that it focuses on the psychological aspects of living with an acquired disability, rather than on disability in general, and considers how practitioners can reduce the psychological burden of identity challenge by the creation of more supportive discursive relationships and services.

\section{Limitations and future research}

The Life Thread Model has been developed to be able to include psychological, social as well as physical aspects within the rehabilitation of people with an acquired disability. Empirical evidence to support the model has been found in studies following stroke [38 - 41] and initial findings are showing that it may also be applicable in conditions such as Parkinson's disease and multiple sclerosis. However, wider studies are needed. The overall principles of the model are clear, but the discursive and material ways in which people approach life transitions following acquired disability are still poorly understood and require more detailed investigation.

Further research is needed to assess the relevance of the model in other long-term conditions including mental health, and to explore the social processes in which people are involved, to successfully create positive identities when living with an acquired disability. Also, despite 
the simplicity of the model, further research will be needed into the application of the model in clinical practice, due to the complex cultural changes that are necessary for successful implementation. Research will identify opportunities and obstacles for healthcare staff wishing to work in a more discursive way, focusing on the 'being' as well as 'doing'.

\section{Conclusion}

By viewing rehabilitation from a perspective which focuses on the psychological and social aspects as well as addressing issues of physical recovery, many new exciting possibilities arise for intervention and treatment. A key aspect of the Life Thread Model is a sense of personhood and shared humanity. We agree with Polaschek [51] who suggested that the human experience of illness and therapy, including interrelationships between clients and healthcare professionals who work with them, should be recognized as central to the provision of healthcare services. In an article reflecting on the nature of medical practice, Neuwirth [59] was concerned that we may have forgotten that healthcare is primarily a humanistic endeavour, that professionals are involved in healing rather than purely technical manipulation, that staff contribute more than just knowledge, and that the patient as a person is more important than the disease. By sharing narratives and entering life worlds, healthcare professionals cannot only gain valuable information about contexts influencing a person's decisions and behaviour, but also support a person at a time when the sense of self is fragile. By sharing narratives and helping people with acquired disabilities to create positive futures, practitioners can acknowledge and value their own shared humanity as well as their technical skills.

\section{Acknowledgements}

The authors would like to thank all of their participants who took part in the research studies which have contributed to this paper. The key study was made possible by a grant from the UK Department of Health Research Studentship Scheme. 


\section{References}

1. Burton C. Living with stroke: A phenomenological study. $J$ Adv Nursing 2000;32(2):301 - 309.

2. Williams SJ. Is anybody there? Critical realism, chronic illness and the disability debate. Sociol Health Illness 1999;21(6): 797 - 819.

3. Berger PL, Luckmann T. The social construction of reality: A treatise in the sociology of knowledge. Harmondsworth, UK: Penguin University Books; 1971.

4. Yardley L, Ussher JM, editors. Material discourses of health and illness. London: Routledge; 1997.

5. Doolittle N. The experience of recovery following lacunar stroke. Rehabil Nursing $1992 ; 17: 122-125$.

6. Bendz M. Rules of relevance after a stroke. Soc Sci Med 2000; 51:713 - 723.

7. Cott CA. Client-centred rehabilitation: Client perspectives. Disabil Rehabil 2004 ;26(24):1411 - 1422.

8. Ironside P, Scheckel M, Wessels C, Bailey M, Powers S, Seeley D. Experiencing chronic illness: Co-creating new understandings Qualitative Health Res 2003;13(2):171 - 183 .

9. Mackay R. Tell them who I was: The social construction of aphasia. Disabil Society $2003 ; 18(6): 811-826$.

10.Campbell C, McCauley G. Doctor-patient relationships in chronic illness: Insights from forensic psychiatry. BMJ 2005; 330:667 - 670 .

11. Paterson B. Myth of empowerment in chronic illness. J Adv Nursing 2001;34(5):574 581.

12.Alaszewski A, Alaszewski H, Potter J. The bereavement model, stroke and rehabilitation: A critical analysis of the use of a psychological model in professional practice. Disabil Rehabil 2004;26(18):1067 - 1078.

13.Susko MA. Caseness and narrative: Contrasting approaches to people who are psychiatrically labelled. JMind Behav 1994; 15(1/2):87 - 112.

14.Murray C, Harrison B. The meaning and experience of being a stroke survivor: An interpretative phenomenological analysis. Disabil Rehabil 2004;26(13):808 - 816.

15.Kadojic D, Vladetic M, Candrlic M, Kadojic M, Dikanovic M, Trkanjec Z. Frequency and characteristics of emotional disorders in patients after ischemic stroke. Eur J Psychiatry 2005;19(2):88 - 95. 
16.Carota A, Berney A, Aybek S, Iaria G, Staub F, Ghika-Schmid F, Annable L, Guex P, Bogousslavsky J. A prospective study of predictors of post-stroke depression. Neurology 2005;64(3):428 - 433.

17.Bennet B. How nurses in a stroke rehabilitation ward attempt to meet the psychological needs of patients who become depressed following stroke. J Adv Nursing 1996;23: 314 $-321$.

18. Bury M. Chronic illness as biographical disruption. Sociol Health Illness 1982;4:167 182.

19.Bury M. The sociology of chronic illness - a review of research and prospects. Sociol Health Illness 1991;13(4):451 - 468.

20. Bury M. Illness narratives: Fact or fiction? Sociol Health Illness 2001;23(3):263 - 285.

21. Williams GH. The genesis of chronic illness: Narrative reconstruction. Sociol Health Illness

$1984 ; 7: 175-200$.

22.Sarbin T. Narrative psychology. The storied nature of human conduct. New York: Praeger; 1986.

23.McAdams DP. Unity and purpose in human lives: The emergence of identity as a life story. In: Rabin AI, Zucker RA, Emmons RA, Frank S, editors. Studying persons and lives. New York: Springer; 1990. pp $148-200$.

24. Carr D. Time, narrative and history. Indianapolis: Indiana University Press; 1986.

25.Reissman C. Narrative analysis - qualitative research methods, series 30. London:

Sage; 1993.

26.Labov W. Language in the inner city: Studies in the Black English vernacular. Philadelphia: University of Philadelphia Press; 1972.

27.Hill CS. Biographical disruption, narrative and identity in stroke: Personal experience in acquired chronic illness. Auto/Biography 1997;5:131 - 144.

28. Ricoeur P. Time and narrative I. Chicago: University of Chicago Press; 1984.

29. Kerby A. Narrative and the self. Bloomington Indiana: Indiana University Press; 1991.

30.Radley A. Making sense of illness - the social psychology of health and disease. London: Sage; 1994.

31. Charon R. Narrative medicine. J Am Medical Assoc 2001; 286:1897 - 1902.

32.Hatem D, Rider EA. Sharing stories: Narrative medicine in an evidence-based world. Patient Educ Counsel 2004;54(3): 251 - 253.

33.Connelly JE. Narrative possibilities - using mindfulness in clinical practice. Perspect 
Biol Med 2005;48(1):84 - 94.

34.Clark F. Occupation embedded in a real-life - interweaving occupational science and occupational therapy. Eleanor Clarke Slagle lecture. Am J Occupat Ther 1993;47(12): $1067-1078$.

35.Mattingly C. In search of the good: Narrative reasoning in clinical practice.

Medical Anthropol Quart 1998;12(3): 273 - 297.

36.Helfrich C, Kielhofner G, Mattingly C. Volition as narrative - understanding motivation in chronic illness. Am J Occupat Ther 1994;48(4):311 - 317.

37.Faircloth CA, Rittman M, Boylstein C, Young ME, van Puymbroeck M.

Energizing the ordinary: Biographical work and the future in stroke recovery narratives. J Aging Stud 2004;18(4):399 - 413.

38.Ellis-Hill CS. New world, new rules: Life narratives and changes in self-concept in the first year after stroke. Unpublished PhD thesis. University of Southampton; 1998.

39.Ellis-Hill C, Horn S. Change in identity and self-concept: A new theoretical approach to recovery following a stroke. Clin Rehabil 2000;14(3):299 - 307.

40.Ellis-Hill C, Payne S, Ward CD. Self-body split: Issues of identity in physical recovery following a stroke. Disabil Rehabil 2000;22(16):725 - 733.

41.Ellis-Hill C. Caring and identity: The experiences of spouses in stroke and other neurological conditions. In: Payne S, Ellis-Hill C, editors. Chronic and terminal illness: New perspectives on being a carer. Oxford: Oxford University Press; 2001. pp $44-63$.

42. Battista J, Almond R. The development of meaning in life. Psychiatry 1973;36:409 427.

43.Myerhoff B, Simic A. Life's career-ageing: Cultural variations on growing old. London: Sage; 1978.

44.Anderson S, Marlett NJ. The language of recovery: How effective communication is critical to restructuring post-stroke life. Top Stroke Rehabil 2004;11(4):55 - 67.

45.Kralik D, Koch T, Price K, Howard N. Chronic illness self-management: Taking action to create order. J Clin Nursing 2004;13:259 - 267.

46.Carpenter C. The experience of spinal cord injury: The individual's perspective - implications for rehabilitation practice. Phys Ther $1994 ; 74: 614-628$.

47. Department of Health. The NHS Plan. London: Dept. of Health; 2000. 
48.Department of Health. National Service Framework for Older people. London: Dept. of Health; 2001.

49.Department of Health. National Service Framework for Long term Conditions. London: Dept. of Health; 2005.

50.Barry C, Stevenson F, Britten N, Barber N, Bradley C. Giving voice to the lifeworld. More humane, more effective medical care? A qualitative study of doctors-patient communication in general practice. Soc Sci Med 2001;53(4): 487 - 505.

51. Polaschek N. Negotiated care: A model for nursing work in the renal setting. $J A d v$ Nursing $2003 ; 42(4): 355-363$.

52. Launer J. Narrative-based primary care. Oxford: Radcliffe Medical Press Ltd; 2002.

53.Burkitt Wright E, Holcombe C, Salmon P. Doctors' communication of trust, care and respect in breast cancer: qualitative study. BMJ 2004;328:864 - 867 .

54.Greenhalgh T, Collard A, Begum N. Sharing stories: Complex intervention for diabetes education in minority ethnic groups who do not speak English. BMJ 2005;330: $628-631$.

55.Maguire P. Improving communication with cancer patients. Eur J Cancer 1999; 35(14): $2058-2065$.

56.McGrath J. Beyond restoration to transformation: Positive outcomes in the rehabilitation of acquired brain injury. Clin Rehabil 2004;18(7):767 - 775.

57.Sumsion T. Law M. A review of evidence on the conceptual elements informing client- centred practice Can J Occupat Ther 2006 Jun;73(3):153 - 162.

58. Whalley Hammell K Perspectives on disability and rehabilitation: Contesting assumptions; challenging practice. London: Churchill Livingstone; 2006.

59. Neuwirth Z. Reclaiming the lost meanings of medicine. Medical J Austral 2002;176:77 -79 . 


\section{Figures}

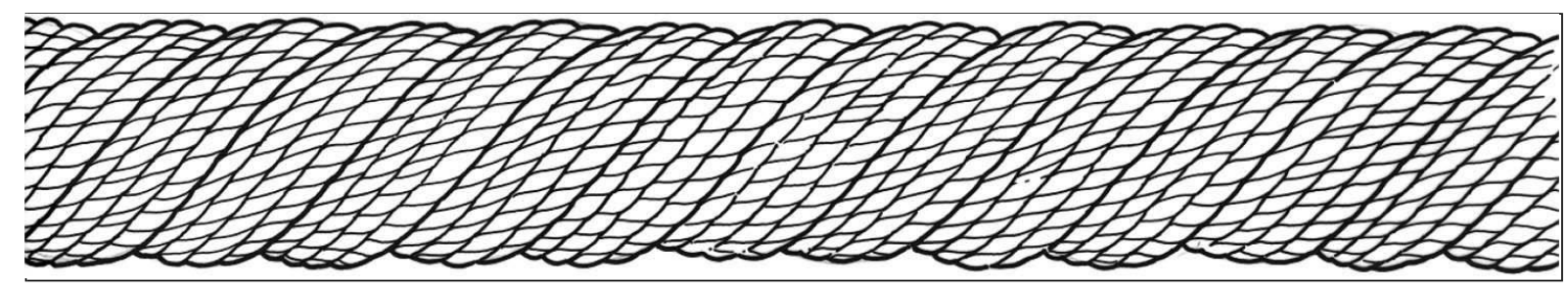

Figure 1. Complete life thread

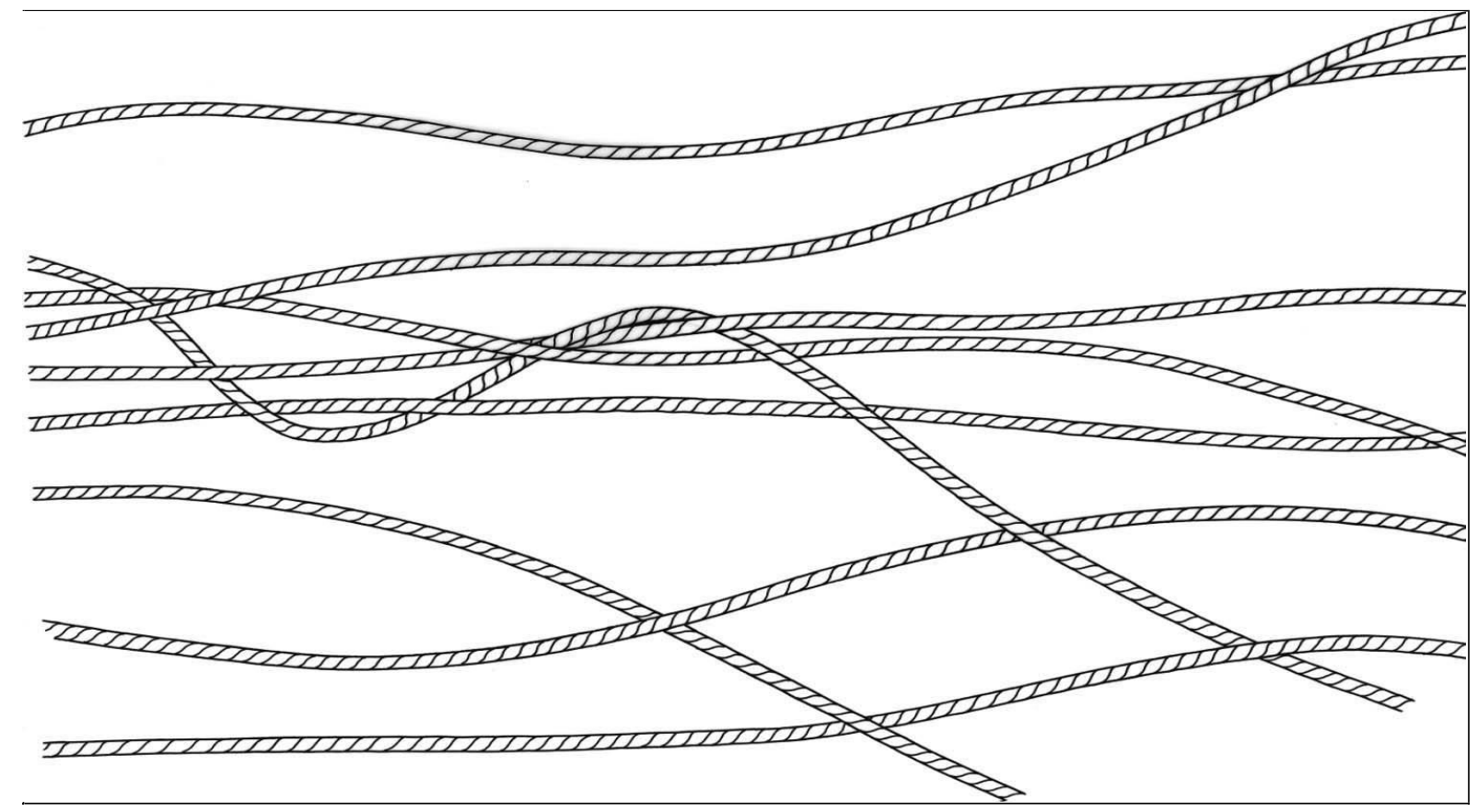

Figure 2. Parallel life threads 
Figure 3. Life threads unravelled.
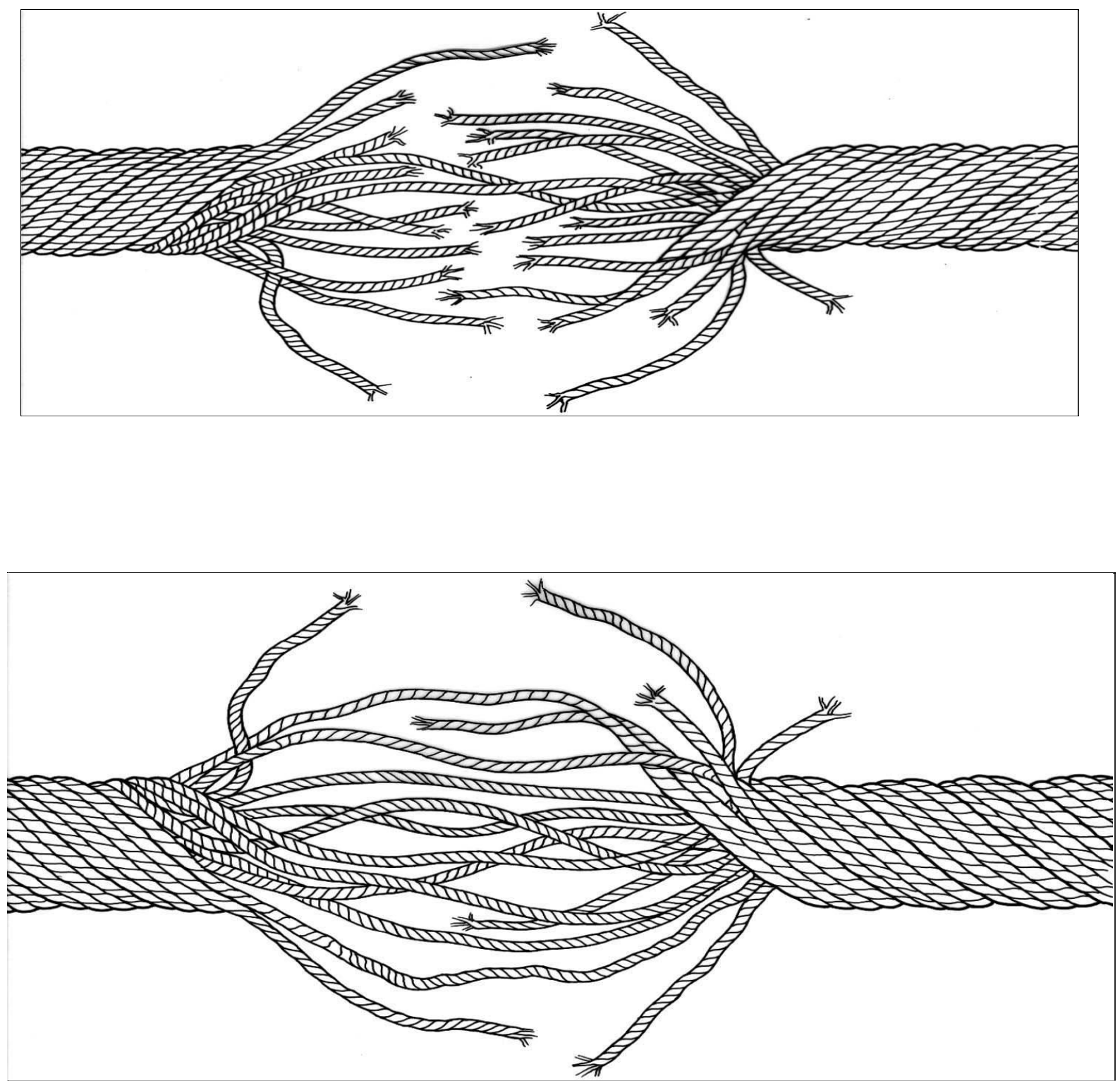

Figure 4. Life threads joining up or tied off. 